DOI: $10.1002 / c p l u .201(($ will be completed by the editorial staff))

\title{
Synthesis and optical properties of new imidazole-based fluorophores with high quantum yields
}

\author{
Marco Lessi, ${ }^{[a]}$ Chiara Manzini, ${ }^{[a]}$ Pierpaolo Minei, ${ }^{[b]}$ Luca Alessandro Perego,${ }^{[a, b]}$ Julien Bloino, ${ }^{[b, c]}$ \\ Franco Egidi, ${ }^{\left[{ }^{[b]}\right.}$ Vincenzo Barone ${ }^{\left[{ }^{[b]}\right.}$ Andrea Pucci ${ }^{*[a]}$ and Fabio Bellina*[a]
}

\begin{abstract}
A series of 1,4-phenylene-spaced bis-imidazoles with fluorescence quantum yields up to 0.90 and large Stokes shifts have been designed and synthesized using recently developed regioselective direct $\mathrm{CH}$-arylation protocols. All the fluorophores show a bright blue-green emission well retained also in the solid state. DFT calculations attributed their excellent luminescent properties to the significant planarization of the molecules in the equilibrium structures of their excited electronic states.
\end{abstract}

Heteroaromatic fluorophores with electron-donor and -acceptor architectures have attracted growing interest for both the understanding of fundamental chemistry and physics and promising applications in diverse fields, ranging from solar energy conversion, ${ }^{[1]}$ to optoelectronic devices ${ }^{[2]}$ and chromogenic materials. ${ }^{[3,4]}$ Recently, it has also been recognized that the use of suitable heteroaromatic backbones usually increases polarizability, stability and thermal and chemical robustness required for fabrication processes. Notably, an impressive amount of attention has been devoted to the development of various organic $\pi$-conjugated compounds because of their highly polarizable structures and resulting efficient intramolecular charge transfer $(\mathrm{CT}) .^{[5,6]}$ The polarizability of these systems depends primarily on their chemical structures, and in particular on the donors and acceptors and on the length and the nature of the $\pi$-conjugated bridge. $^{[1,5,6]}$ In contrast to inorganic materials, organic materials with readily polarizable push-pull systems have been also recognized as tunable fluorophores for non-linear optics (NLO). ${ }^{[7,8]}[9]$

As far as heteroaromatics are concerned, imidazole possesses a wide range of interesting properties such as acidbase character, transition metal-binding activity, thermal and chemical robustness, and tautomerism, and has found diverse applications in ionic liquids, ligands, and drugs. Moreover,

[a] F. Bellina, M. Lessi, C. Manzini, L. A. Perego, A. Pucci

Dipartimento di Chimica e Chimica Industriale

Università di Pisa

Via Risorgimento 35, 56126 Pisa (Italy)

E-mail: fabio.bellina@unipi.it; andrea.pucci@unipi.it

[b] L. A. Perego, F. Egidi, V. Barone, J. Bloino, P. Minei

Classe di Scienze

Scuola Normale Superiore

Piazza dei Cavalieri 7, 56126 Pisa (Italy)

[c] J. Bloino

Istituto di chimica dei composti organo metallici

Consiglio Nazionale per le Ricerche

Area della Ricerca, via Moruzzi 1, 56125 Pisa (Italy) imidazole and benzimidazole moieties have been utilized as suitable $\pi$-conjugated spacers in charge-transfer chromophores and useful DNA-binding probes for fluorescence microscopy and flow cytometry. ${ }^{[10,11]}$

To the best of our knowledge, no published study has been carried out on unsymmetrically substituted $p$-phenylene-linked bis-imidazoles. Nevertheless, they seem promising in terms of optical properties, such as large Stokes shifts and high fluorescence quantum yields, as can be inferred by comparison with similar compounds (e.g. oxazole-containing POPOP derivatives) already described in the literature. ${ }^{[12]}$ Moreover, unsymmetrical derivatives are likely to have enhanced CT upon excitation in comparison to symmetrical compounds.

The present work concerns the application of palladiumcatalyzed selective direct $\mathrm{C}-\mathrm{H}$ arylation reactions to the synthesis of novel fluorophores 1a-c featuring a 1,4phenylene-linked bis-imidazole scaffold, which display interesting spectroscopic properties such as high Stokes shifts and relevant fluorescence quantum yields. It is interesting to observe that the recent advances in transition metal-catalyzed direct $\mathrm{C}-\mathrm{H}$ arylation of heterocycles, that offer an alternative reliable method to classical cross-coupling methodology, have been little exploited to design neat syntheses of heterocyclic fluorophores. ${ }^{[10,13-22]}$ We selected a methoxy, a methyl and a cyano group as substituents on the terminal phenyl ring of 1 since they are typical examples of electron-releasing, electron neutral and electron-withdrawing groups, respectively (Hammett's $\sigma_{\mathrm{p}}$ constants: ${ }^{[23]} \mathrm{CN}+0.66$; Me -0.17; MeO -0.27). For this reason, they are likely to be representative of other similar substituents for what concerns both synthetic issues and spectroscopic properties.

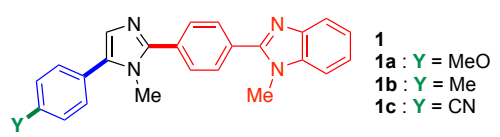

Scheme 1. Chemical Structures of Compounds 1a-c.

Compounds 1a-c were synthesized according to a simple and scalable synthetic procedure involving two sequential palladium-catalyzed regioselective direct $\mathrm{C}-\mathrm{H}$ arylation reactions starting from 1 -methyl- $1 \mathrm{H}$-imidazole (2) (Scheme 2). In detail, 5-aryl-1-methyl-1H-imidazoles $4 a-c$ were efficiently prepared by a palladium catalyzed direct $\mathrm{C} 5-\mathrm{H}$ arylation reaction, promoted by $\mathrm{Bu}_{4} \mathrm{NOAc}$, involving 2 and aryl bromides 


\section{ChemPlusChem}

\section{Communications
www.chempluschem.org}

3a-c as recently described by us. ${ }^{[24]}$ The 5 -arylimidazoles 4 a-c so obtained were then reacted with 2-(4-bromophenyl)-1methyl- $1 \mathrm{H}$-benzimidazole $(5)$ according to our recent protocol for the palladium- and copper-promoted regioselective direct $\mathrm{C} 2-\mathrm{H}$ arylation reaction under base- and ligand-free conditions. ${ }^{[25]}$ Intermediate $\mathbf{5}$ has been obtained by the condensation of 4-bromobenzaldehyde with $\mathrm{N}$-methyl-1,2benzenediamine and oxidation (see ESI). In this way, the required fluorophores $1 \mathrm{a}-\mathrm{c}$ were isolated in $42-88 \%$ yields. All the intermediates and products were characterized by NMR spectroscopy and Mass spectrometry, with satisfactory results.

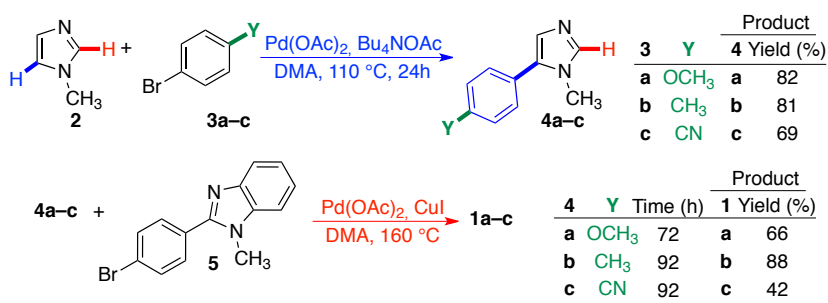

Scheme 2. Synthesis of fluorophores 1a-c.

All the optical features of compounds 1a-c are summarized in Table 1. Notably, the absorption spectrum of derivatives $\mathbf{1 a}$ and $\mathbf{1 b}$ are practically the same, whereas 1c shows an absorption band about $10 \mathrm{~nm}$ red-shifted (Figure 1)

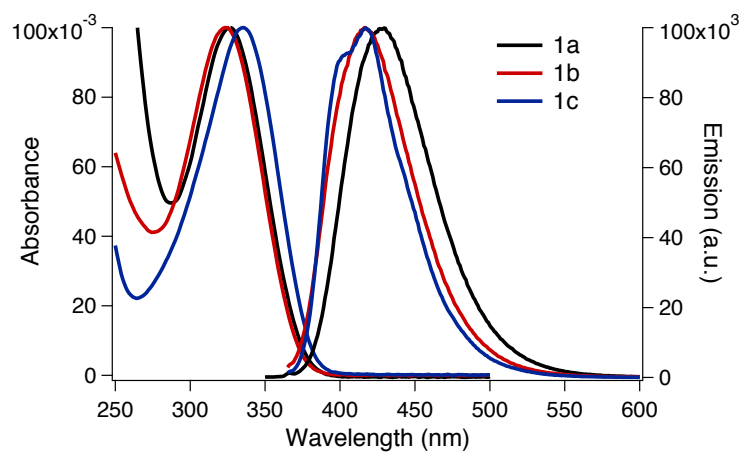

Figure 1. Absorbance (left) and emission (right) spectra of $5 \mu \mathrm{M}$ dye solutions in THF

The emission spectrum becomes progressively red-shifted in the order $\mathbf{1 c}, \mathbf{1 b}, \mathbf{1 a}$, and the Stokes shift (S) thus increases in the same direction (Figure 1). The fluorescence quantum yields $(\Phi)$ of the three fluorophores were also determined to have a quantitative picture (Table 1). All molecules resulted strong emitters with quantum yields comprised between $83 \%$ and $90 \%$. The lowest $\Phi$ corresponding to 1c, which is characterized by the lowest $S(82 \mathrm{~nm})$, and the highest overlapping between absorbance and emission (Figure 1).

The product between $\varepsilon$ and $\Phi$ was also calculated for making comparisons between the different fluorophores. This parameter is defined as the brightness (B) of the dye, accounting for both the amount of light absorbed and the quantum efficiency of the fluorophore. B values of around $30,000 \mathrm{M}^{-1} \mathrm{~cm}^{-1}$ are among the highest calculated for fluorophores in the same wavelength region (for example, Pyrene brightness $\left.=32,000 \mathrm{M}^{-1} \mathrm{~cm}^{-1}\right)$. ${ }^{[26]}$

Table 1 Spectroscopic properties of fluorophores $1 \mathrm{a}-\mathbf{c}$ dissolved in THF

\begin{tabular}{lllllll} 
& $\lambda_{\text {abs }}[\mathrm{nm}]$ & $\varepsilon\left[\mathrm{M}^{-1} \mathrm{~cm}^{-1}\right]$ & $\lambda_{\mathrm{em}}[\mathrm{nm}]$ & $\mathrm{S}[\mathrm{nm}]$ & $\Phi_{\mathrm{f}}^{[\mathrm{a}]}$ & $\mathrm{B}\left[\mathrm{M}^{-1} \mathrm{~cm}^{-1}\right]^{[\mathrm{b}]}$ \\
\hline 1a & 325 & 36,000 & 428 & 103 & 0.90 & 32,400 \\
1b & 320 & 31,000 & 415 & 95 & 0.88 & 27,280 \\
1c & 335 & 39,000 & 397 & 82 & 0.83 & 32,370 \\
\hline
\end{tabular}

[a] Fluorescence quantum yield $(\Phi)$ was determined relative to quinine sulphate in $0.1 \mathrm{M} \mathrm{H}_{2} \mathrm{SO}_{4}(\Phi=0.54)$. [b] ) The brightness (B) of fluorophores are calculated as the product of the absorption coefficient $\varepsilon$ and $\Phi$

It is also reported that the intensity of fluorescence emission $I_{f}$ observed at a wavelength $\lambda_{f}$ should vary with the concentration of the emitting species $c$ according to the following equation ${ }^{[27]}$

$$
I_{f}=k\left(\lambda_{f}\right) I_{o}\left(\lambda_{e}\right)\left[1-10^{-\epsilon\left(\lambda_{e}\right) l c}\right]
$$

in which $k$ is a proportionality constant which depends on experimental conditions, $I_{o}$ is the intensity of the incident light at the wavelength $\lambda_{e}, I$ is the path length and $\varepsilon$ the molar extinction coefficient. The fluorescence intensity is thus expected to increase with concentration but only for absorbances usually less than 0.1. Deviations from a linear behaviour occurs at higher absorbances due to a variety of reasons, among which radiative transfer phenomena or the formation of aggregates are the most representative. ${ }^{[27]}$ 1a-c compounds start to display self-quenching properties for concentrations higher than $10^{-5} \mathrm{M}$ (absorbances of about 0.30 0.35), as reported in Figure S1 (see ESI). Nevertheless, all fluorophores exhibit bright blue-green emissions in the solid state as well (Figures 2 and 3). $\mathbf{1 b}$ and 1c powders emit significantly red-shifted fluorescence as compared to $1 \mathrm{a}$ and THF solutions. This phenomenon may be addressed to the higher electronic coupling resulting from aggregation of their respective molecules or planarization of their chromophore backbone due to the increased conjugation.

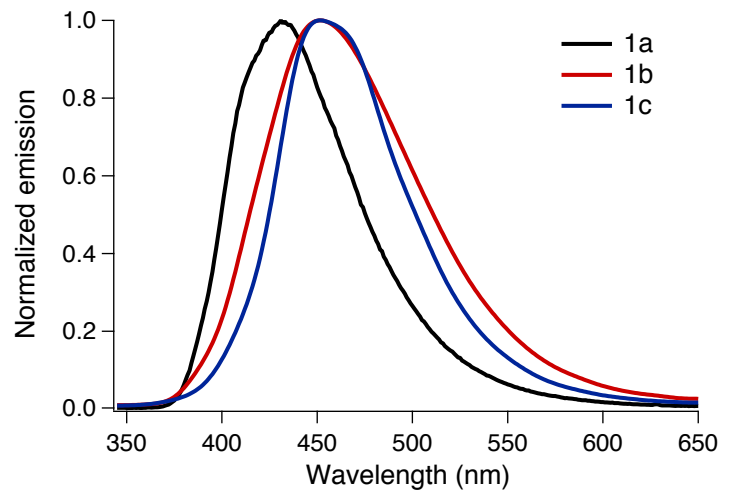

Figure 2. Normalized emission spectra of solid dyes 1a, 1b and 1c 


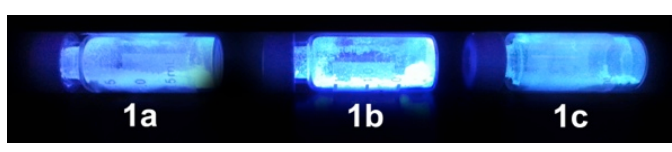

Figure 3. Pictures of the different solid samples taken under the illumination at $366 \mathrm{~nm}$.

Theoretical calculations at the (TD)-DFT/CAMB3LYP/N07D/PCM level of theory were also performed to better understand the peculiar photophysical properties of the 1a-c (see ESI). Some qualitative insights can be gained by inspection of frontier molecular orbital (MO) graphical representations, since the observed band is almost entirely due to HOMO-LUMO transition, as can be inferred by inspection of the $\mathrm{Cl}$ expansion coefficients. The $\mathrm{MO}$ isosurfaces of compounds $\mathbf{1 a}$ and $\mathbf{1 c}$, i.e. those bearing respectively the electron-releasing and electron-withdrawing groups, are reported in Figure 4 and 5 . For both 1a and 1c the HOMO is spread approximately equally all over the molecule, but the appearance of the LUMO is very different between the two compounds. For 1a there is a significant charge transfer from the methoxy-substituted phenyl ring towards the benzimidazole nucleus. For 1c the charge transfer is in the opposite direction and goes from the benzimidazole moiety to the $\mathrm{CN}$-substituted phenyl ring.

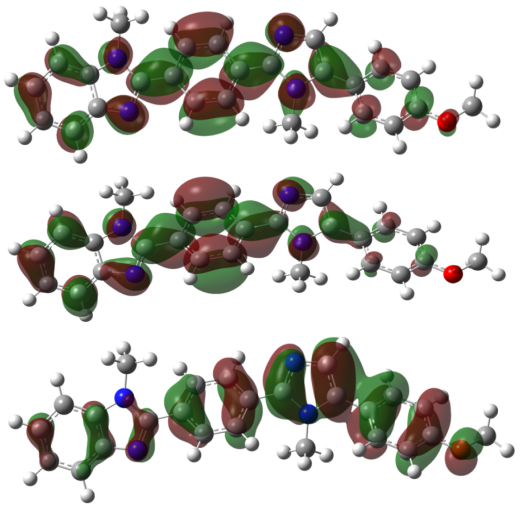

Figure 4. MO surfaces for 1a. Bottom: HOMO (ground state geometry) Middle: LUMO (ground state geometry). Top: LUMO (excited state optimized geometry).

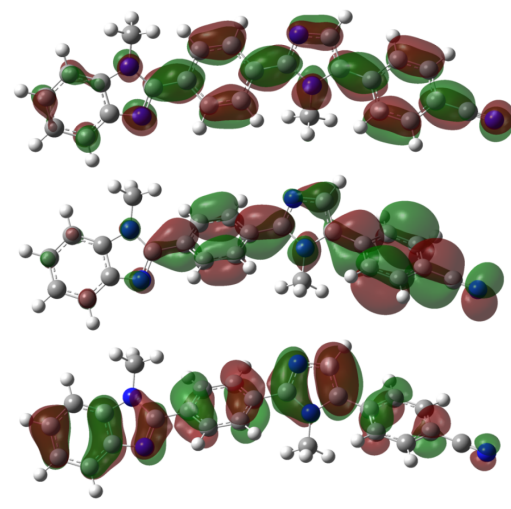

Figure 5. MO surfaces for 1c. Bottom: HOMO (ground state geometry) Middle: LUMO (ground state geometry). Top: LUMO (excited state optimized geometry).
Dipole moments are obviously higher in the excited state than in the ground state for both $1 \mathrm{a}(4.75$ and $3.46 \mathrm{D}$, respectively) and 1c (5.82 and $5.05 \mathrm{D}$, respectively) and are in approximately opposite directions, as depicted in Figure S2 (see ESI).

Most interestingly, we observed that geometry optimization of the excited electronic states makes the individual rings significantly more coplanar in both cases (computed dihedral angles are shown in Figure 6) and the charge transfer is attenuated.
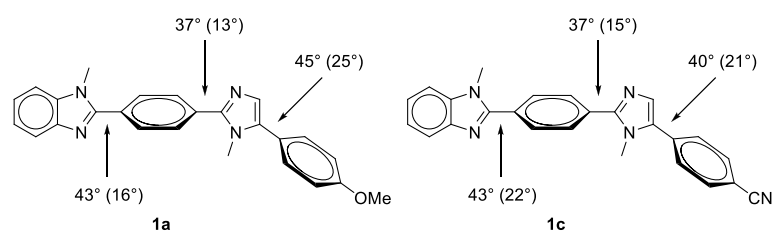

Figure 6. Dihedral angles for compounds 1a and 1c. Values after excited state geometry optimization are reported in parentheses.

The significant planarization of the molecule in the equilibrium structure of the excited electronic state is a consistent explanation of the high Stokes shifts observed, as already reported in the literature for analogous POPOP-type dyes. ${ }^{[28]}$ Moreover, the higher planarization shown by $1 \mathrm{c}$ compared to 1a possibly explain its red-shifted emission in the solid state.

In conclusion, a highly efficient access to a set of 1,4phenylene-linked bis-imidazole fluorophores is reported, which takes advantage of sequential regioselective palladiumcatalyzed direct arylation reactions starting from 1-methyl-1 $\mathrm{H}$ imidazole (2). Compounds 1a-c showed in solution Stokes shifts up to $103 \mathrm{~nm}$, very high fluorescence quantum yields and their bright blue-green emission well retained in the solid state. Quantum mechanical calculations at the DFT level suggested that the excellent luminescent properties of this class of compounds are due to the more planar structure of the chromophoric units in the excited electronic state.

These findings could be exploited quite reliably for the realization of a large library of luminescent dyes with relevant optical features also in the visible-near IR optical region.

\section{Experimental Section}

General procedure for the synthesis of 2-(4-aryl-1-methyl$1 H$-imidazol-2-yl)phenyl)-1-methyl-1 $H$-benzo[d]imidazoles $1 \mathrm{a}-\mathrm{c}^{[29]}$

A two necked flask equipped with a magnetic stirrer and a reflux condenser was charged with the appropriate 5-aryl-1methyl-1H-imidazole $4 a-c^{24}$ (0.75 mmol), 2-(4-bromophenyl)-1methyl-1H-benzo[d]imidazole 5 (323.0 $\mathrm{mg}, 1.13 \mathrm{mmol})$, $\mathrm{Pd}(\mathrm{OAc})_{2}(8.4 \mathrm{mg}, 0.04 \mathrm{mmol})$ and Cul $(285.7 \mathrm{mg}, 1.50 \mathrm{mmol})$. The apparatus was closed with a silicone septum, evacuated and back-filled with argon. The latter procedure was repeated three times. Anhydrous $N, N$-dimethylacetamide $(4.0 \mathrm{~mL})$ was added by syringe against a positive pressure of argon. The reaction mixture was stirred at $160{ }^{\circ} \mathrm{C}$. The degree of completion of the reaction and the composition of the reaction mixture was established on the basis of GLC and GLC-MS 


\section{ChemPlusChem}

\section{www.chempluschem.org}

analyses of samples of the crude reaction mixtures diluted with $\mathrm{CH}_{2} \mathrm{Cl}_{2}$ and washed with saturated $\mathrm{NH}_{4} \mathrm{Cl}$ solution to which a few drops of concentrated aqueous ammonia had been added. After cooling to room temperature, the reaction mixture was diluted with $\mathrm{CH}_{2} \mathrm{Cl}_{2}(100 \mathrm{~mL})$ and poured into a saturated aqueous $\mathrm{NH}_{4} \mathrm{Cl}$ solution, and the resulting mixture was stirred in the open air for $0.5 \mathrm{~h}$ and then extracted with $\mathrm{CH}_{2} \mathrm{Cl}_{2}$. The organic extracts were washed with saturated brine, dried, filtered over Celite and the filtrate was concentrated under reduced pressure. The residue was purified by flash chromatography on silica gel with a mixture of $\mathrm{CH}_{2} \mathrm{Cl}_{2} / \mathrm{MeOH}$ (95:5) as eluent. The chromatographic fractions containing the required compound were collected and concentrated under reduced pressure. This procedure was employed to prepare compounds 1a-c (Scheme 2).

\section{2-(4-(5-(4-Methoxyphenyl)-1-methyl-1H-imidazol-2-} yl)phenyl)-1-methyl-1 $H$-benzo[d]imidazole (1a)

The reaction between 5 and $4 a$ according to the general procedure $(72 \mathrm{~h})$ gave $\mathbf{1 a}$ in the form of an off-white amorphous solid (195.1 mg, $66 \%$ ): m.p. $265-269{ }^{\circ} \mathrm{C}$; El-MS $\mathrm{m} / \mathrm{z}(\%): 395$ (27), $394\left(100, \mathrm{M}^{+}\right), 393$ (51); ${ }^{1} \mathrm{H}$ NMR $(300 \mathrm{MHz}$, $\left.\mathrm{CDCl}_{3}\right): \delta=7.92-7.83(\mathrm{~m}, 5 \mathrm{H}), 7.44-7.32(\mathrm{~m}, 5 \mathrm{H}), 7.15(\mathrm{~s}, 1 \mathrm{H})$, $7.01(\mathrm{~d}, \mathrm{~J}=8.7 \mathrm{~Hz}, 2 \mathrm{H}), 3.93(\mathrm{~s}, 3 \mathrm{H}), 3.87(\mathrm{~s}, 3 \mathrm{H}), 3.71(\mathrm{~s}, 3 \mathrm{H})$ ppm; ${ }^{13} \mathrm{C}$ NMR $\left(100.6 \mathrm{MHz}, \mathrm{CDCl}_{3}\right): \delta=159.6,153.2,148.0$, $143.0,136.7,135.9,132.3,130.2$, 129.5, 129.3, 128.7, 128.4, $127.4,123.0,122.6,120.4,119.9,119.5,114.3,109.6,55.6$, 34.0, 29.7 ppm; elemental analysis calcd (\%) for $\mathrm{C}_{25} \mathrm{H}_{22} \mathrm{~N}_{4} \mathrm{O}: \mathrm{C}$ 76.12, H 5.62; found: C 76.63, H, 5.58

\section{1-Methyl-2-(4-(1-methyl-5-p-tolyl-1H-imidazol-2-yl)phenyl)- $1 H$-benzo[d]imidazole (1b)}

The reaction between $\mathbf{5}$ and $\mathbf{4 b}$ according to the general procedure (92 h) gave $\mathbf{1 b}$ in the form of an off-white amorphous solid (250.8 mg, 88\%): m.p. $249-252{ }^{\circ} \mathrm{C}$; EI-MS $\mathrm{m} / \mathrm{z}(\%): 379$ (25), $378\left(\mathrm{M}^{+}, 100\right), 377(66) ;{ }^{1} \mathrm{H}$ NMR (300 MHz, $\left.\mathrm{CDCl}_{3}\right): \delta=7.83-7.93(\mathrm{~m}, 5 \mathrm{H}), 7.28-7.41(\mathrm{~m}, 7 \mathrm{H}), 7.23(\mathrm{~s}, 1 \mathrm{H})$, $3.93(\mathrm{~s}, 3 \mathrm{H}), 3.73(\mathrm{~s}, 3 \mathrm{H}), 2.42(\mathrm{~s}, 3 \mathrm{H}) \mathrm{ppm} ;{ }^{13} \mathrm{C}$ NMR $(50.3$ $\left.\mathrm{MHz}, \mathrm{CDCl}_{3}\right): \delta=153.3,143.2,138.3,136.9,136.3,132.3$, $130.5,129.9,129.1,128.9,127.7,127.3,123.2,122.8,120.2$, $109.9,34.2,32.1,21.6 \mathrm{ppm}$; elemental analysis calcd (\%) for $\mathrm{C}_{25} \mathrm{H}_{22} \mathrm{~N}_{4}$ : C 79.34, H 5.86; found: C 79.01, H 5.89.

\section{4-(1-Methyl-2-(4-(1-methyl-1H-benzo[d]imidazol-2- yl)phenyl)-1 $H$-imidazol-5-yl)benzonitrile (1c)}

The reaction between 5 and $4 c$ according to the general procedure $(92 \mathrm{~h})$ gave 1c in the form of off-white amorphous solid (122.7 mg, 42\%): m.p. $279-282{ }^{\circ} \mathrm{C}$; El-MS m/z (\%): 391 (4), $389\left(\mathrm{M}^{+}, 100\right), 388(83) ;{ }^{1} \mathrm{H}$ NMR $\left(300 \mathrm{MHz}, \mathrm{CDCl}_{3}\right): \delta=$ $7.94(\mathrm{~d}, J=8.2 \mathrm{~Hz}, 1 \mathrm{H}), 7.88(\mathrm{~d}, J=8.8 \mathrm{~Hz}, 1 \mathrm{H}), 7.84(\mathrm{~s}, 1 \mathrm{H})$, $7.77(\mathrm{~d}, J=8.2 \mathrm{~Hz}, 1 \mathrm{H}), 7.61(\mathrm{~d}, J=8.0 \mathrm{~Hz}, 1 \mathrm{H}), 7.32-7.46(\mathrm{~m}$ $4 \mathrm{H}), 3.94(\mathrm{~s}, 3 \mathrm{H}), 3.78(\mathrm{~m}, 3 \mathrm{H}) \mathrm{ppm} ;{ }^{13} \mathrm{C}$ NMR $(50.3 \mathrm{MHz}$, $\left.\mathrm{CDCl}_{3}\right): \delta=153.0,150.3,143.1,136.9,134.7,134.4,133.0$, 131.7, 131.1, 130.0, 129.8, 129.3, 128.7, 123.4, 122.9, 120.1, $118.8,111.6,110.0,34.6,32.2 \mathrm{ppm}$; elemental analysis calcd (\%) for $\mathrm{C}_{25} \mathrm{H}_{19} \mathrm{~N}_{5}$ : C 77.10; $\mathrm{H} 4.92$; found: C 76.96, H 4.96.
Keywords: C-C coupling • Fluorescence - Direct Arylation • Imidazoles $\cdot$ Computational Chemistry

[1] A. Hagfeldt, G. Boschloo, L. Sun, L. Kloo, H. Pettersson Chem. Rev. 2010, 110, 6595-6663

[2] G. S. He, L.-S. Tan, Q. Zheng, P. N. Prasad Chem. Rev. 2008, 108, 1245-1330.

[3] F. Ciardelli, G. Ruggeri, A. Pucci, Chem. Soc. Rev. 2013, 42, 857-870.

[4] P. Minei, A. Battisti, S. Barondi, M. Lessi, F. Bellina, G. Ruggeri, A. Pucci ACS Macro Letters. 2013, 2, 317-321.

[5] M. P. Eng, B. Albinsson, Angew. Chem. Int. Ed. 2006, 45, 5626-5629

[6] Z. R. Grabowski Pure and Applied Chemistry. 1993, 65, 1751-1756.

[7] S.-i. Kato, M. T. R. Beels, P. La Porta, W. B. Schweizer, C. Boudon, J.-P. Gisselbrecht, I. Biaggio, F. Diederich Angew. Chem. Int. Ed. 2010, 49, 6207-6211.

[8] M. Usui, H. Fukumoto, T. Yamamoto Bull. Chem. Soc. Jpn. 2010, 83, 1397-1399.

[9] X. Meng, W. Zhu, H. Tian in Introduction to Organic Electronic and Optoelectronic Materials and Devices, (Eds.: S.-S. Sun, L. R. Dalton), CRC Press, Boca Raton (USA), 2008, pp.192-172.

[10] J. Kulhánek, F. Bureš, O. Pytela, T. Mikysek, J. Ludvík Chemistry An Asian Journal. 2011, 6, 1604-1612.

[11] J.-M. Petit, M. Denis-Gay, M.-H. I. n. Ratinaud, Biology of the Cell. 1993, 78, 1-13.

[12] N. V. KrishnaMurthy, A. R. Reddy, B. Bhudevi, J Fluoresc. 2008, 18, 29-34.

[13] L. Ackermann, R. Vicente, A. R. Kapdi, Angew. Chem. Int. Ed. 2009, 48, 9792-9826.

[14] D. Alberico, M. E. Scott, M. Lautens, Chem. Rev. 2007, 107, 174-238.

[15 F. Bellina, R. Rossi, Tetrahedron. 2009, 65, 10269-10310.

[16] K. Masui, A. Mori, K. Okano, K. Takamura, M. Kinoshita, T. Ikeda Organic Letters. 2004, 6, 2011-2014.

[17] G. P. McGlacken, L. M. Bateman, Chem. Soc. Rev. 2009, 38, 24472464.

[18] L. G. Mercier, M. Leclerc, Acc. Chem. Res. 2013, 46, 1597-1605.

[19] A. Mori, A. Sugie, Bull. Chem. Soc. Jpn. 2008, 81, 548

[20] J. Roger, A. L. Gottumukkala, H. Doucet, ChemCatChem. 2010, 2 , 20-40.

[21] C. Verrier, C. Fiol-Petit, C. Hoarau, F. Marsais, Organic \& Biomolecular Chemistry. 2011, 9, 6215-6218.

[22] J. Yamaguchi, A. D. Yamaguchi, K. Itami, Angew. Chem. Int. Ed.. 2012, 51, 8960-9009.

[23] C. Hansch, A. Leo, R. W. Taft, Chem. Rev. 1991, 91, 165-195

[24] F. Bellina, M. Lessi, C. Manzini, Eur. J. Org. Chem. 2013, 5621-5630.

[25] F. Bellina, S. Cauteruccio, R. Rossi, J. Org. Chem. 2007, 72, 85438546

[26] L. D. Lavis, R. T. Raines, ACS Chemical Biology. 2008, 3, 142-155.

[27] B. Valeur, M. N. Berberan-Santos in Molecular Fluorescence: Principles and Applications, Wiley-VCH, Weinheim, 2012.

[28] R. Y. Iliashenko, N. Y. Gorobets, A. O. Doroshenko, Tetrahedron Lett. 2011, 52, 5086-5089.

[29] (a) F. Bellina, C. Calandri, S. Cauteruccio, R. Rossi, Tetrahedron 2007, 63, 1970-1980; (b) F. Bellina, S. Cauteruccio, A. Di Fiore, C. Marchetti, R. Rossi, Tetrahedron 2008, 64, 6060-6072; (c) F. Bellina, S. Cauteruccio, R. Rossi, Eur. J. Org. Chem. 2006, 1379-1382.

Received: ((will be filled in by the editorial staff))

Published online: ((will be filled in by the editorial staff))

\section{Acknowledgements}

This work was supported by the Fondazione Pisa under "POLOPTEL" project no. $167 / 09$ and by MIUR-FIRB (RBFR122HFZ). 


\section{Entry for the Table of Contents}

\section{COMMUNICATION}

Direct C-H arylation at work!

Regioselective $\mathrm{CH}-5$ and $\mathrm{CH}-2$ direct arylations of 1-methylimidazole allowed the simple access to a new class of push-pull heteroaromatic fluorophores. DFT calculations attributed their large Stokes shifts and high fluorescence quantum yields to the significant planarization of the molecules in the equilibrium structures of their excited electronic states.

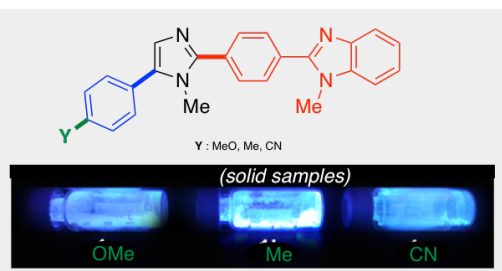

Marco Lessi, Chiara Manzini, Pierpaolo Minei, Luca Alessandro Perego, Julien Bloino, Franco Egidi, Vincenzo Barone, Andrea Pucci* and Fabio Bellina*

Page No. - Page No.

Synthesis and optical properties of new imidazole-based fluorophores with high quantum yields 